densities. There is clearly considerable diversity in the effect of changing ion density on different types of biological, response-a diversity which goes even deeper than appears from these curves, since the shape of the curve even for the production of a given type of injury in a particular entity, such as a chromosome, is different at different developmental stages in the cell cycle ${ }^{10-15}$. This diversity may at some future time prove valuable as an aid to the analysis of some complex reaction, such as tumour regression, into its constituent factors, but at present we are only at the threshold of a coherent interpretation of these curves. The recent successful interpretation of chromosome break data ${ }^{14}$ may provide a starting point.

The data for tumour response are rather fragmentary. The value of $\eta$ has been measured for the effect of $\gamma$-rays, X-rays and fast neutrons on mouse tumour irradiated in vitro ${ }^{23,19,22}$. From Fig. 2 it will be seen that within this limited range, tumour response closely follows the course of the curve for the lethal effect on bean roots. Further, it has been found that $\eta_{\gamma}^{N}$ has a very large value $(\sim 20)$ for the effect of (D-D) neutrons on mouse tumour irradiated in vivo ${ }^{20}$. The bean root curve (Fig. 2) may therefore be taken as a rough guide to the probable influence of ion density on tumour response. The mean ion densities of the recoil proton tracks from neutrons generated in several ways are indicated on the figure. It is clear that these neutron beams may be expected to differ considerably in biological efficiency.

The successful treatment of a tumour does not depend on a single biological effect, but on at least two effects, the tumour reaction and the normal tissue reaction, and possibly on others.

Stone and Larkin ${ }^{1}$ formed an estimate of the relative effectiveness of neutrons and $\mathrm{X}$-rays for one important normal tissue reaction, namely, the production of a given degree of erythema of the skin. The corresponding value of $\eta$ has been plotted and lies close to the same curve (Fig. 2). It is interesting to note also that they observed less severe skin reactions than expected when changing from treatment with the 37 -in. to the 60 -in. cyclotron, but the possibility that the difference lay in the method of dose measurement could not be excluded. Any superiority of neutrons over X-rays, however, may be taken to indicate that $\eta$ is increasing more rapidly with ion density for the tumour than for normal tissue, and therefore in the light of Fig. 2 we may hazard a guess that if neutrons from the 60-in. cyclotron showed some superiority over $\mathrm{X}$-rays, neutrons from the 37-in. cyclotron or (D-D) neutrons would show an even greater superiority. If it is desirable to retain the advantage of the high neutron intensity obtainable from the larger cyclotrons, it might be found to be of therapeutic value to slow down the neutrons somewhat by passage through wax before entering the body.

The optimum neutron energy can, of course, only be found empirically. There is no reason for believing that it will coincide with the neutron energy for which $\eta$ is maximum for the lethal effect on bean roots. Indeed, should the course of the curve for $\eta$ (tumour)

$\frac{\eta(\text { tumour })}{\eta \text { normal tissue })}$

probably choose to use neutrons somewhat faster than (D-D) neutrons, so that, as a result of the slowing down of the neutrons in passing through the body, an energy corresponding to the maximum value of this ratio is just reached at the site of the tumour. In this way, for equal physical doses, the skin would be less damaged because exposed to a radiation of relatively lower efficiency, and at the same time the tissues deeper than the tumour would not be excessively exposed.

When a 60-in. cyclotron is used as a source of neutrons, it is likely that the skin is in a relatively favourable position, being exposed to very fast neutrons, and that the tissues deeper than the tumour, through being exposed to slower neutrons, are relatively more damaged (for equal doses) than the normal tissue at the site of the tumour. This may perhaps be the reason why Stone and Larkin observed very severe systemic reactions and diarrhoea in patients receiving radiation to the upper abdomen, though the skin, which received a very much larger dose (ionization per unit volume of tissue), was not excessively damaged.

1 Stone and Larkin, Rad., 39, 608 (1942).

${ }^{2}$ Timof́eff-Ressovsky and Zimmer, Strth,, 54, 265 (1935).

${ }^{3}$ Dempster, Proc. U.S. Nat. Acad. Sci., 27, 249 (1941).

- Wollman, Holweek and Luria, NATURE, 145, 935 (1940).

${ }^{5}$ Lea, Nature, 146, 137 (1940).

- Lea and Salaman, Brit. J. Exp. Path., 23, 27 (1942).

${ }^{7}$ Lea and Smith, Parasit., 34, 227 (1942).

${ }^{8}$ Lea, Faines and Coulson, Proc. Roy. Soc., B, 122, 47 (1936); 123, 1 (1937).

- Lea, Haines and Betscher, J. Hyg., 41, 1 (1941).

${ }^{10}$ Marshak, Proc. Soc. Exp. Biol. and Med., 41, 176 (1939).

11 Giles, Proc. U.S. Nat. Acad. Sci., 26, 567 (1940).

12 Thoday, J. Genetics, 43, 189 (1942).

${ }^{13}$ Marshak, Proc. U.S. Nat. Acad. Sci., 28, 29 (1942).

${ }^{14}$ Lea and Catcheside, $J$. Genetics, 44, 216 (1942).

${ }^{15}$ Marshak, Rad., 39, 621 (1942).

${ }^{16}$ Zirkle and Lampe, Amer. J. Rönt., 39, 613 (1938).

${ }^{17}$ Gray, Read and Mottram, NATuRE, 144, 478 (1939).

18 Gray and Read, Brit. J. Rad., 15, 11 (1942); 15, 39 (1942); 15 , $72(1942) ; 15,320$ (1942); 16, 125 (1943).

19 Axelrod, Aebersold and Laurence, Proc. Soc. Exp. Biol. and Med., 48, 251 (1941).

${ }^{20}$ Gray, Mottram and Read (unpublished).

${ }_{21}$ Gray, Mottram, Read and Spear, Brit. J. Rad., 13, 371 (1940).

${ }^{22}$ Aebersold and Lawrence, J. H., Amer. Rev. Physiol., 4, 25 (1942).

${ }^{23}$ Suguira, Amer. J. Cancer, 37, 445 (1939).

${ }^{24}$ Mottram and Gray, Brit. J. Rad., 13, 31 (1940).

\section{ULTRA-HIGH ELECTROMAGNETIC FREQUENCIES}

A $\mathrm{T}$ a joint meeting of the Institute of Radio A Engineers and the American Institute of Electrical Engineers held on January 28, G. C. Southworth explained how micro-waves are adding to the tools of the communications engineer (Bell Lab. Rec., 21, No. 7 ; March, 1943). Briefly out. lining the conquest of the frequencies, Dr. South. worth mentioned the need of television and communication in general for more and wider channels as one of the prime forces in the advance into the micro-waves. Other desirable features of the 'micro' region are the small size of antennæ and their high directivity, and the fact that the waves follow the line of sight and thus do not interfere with signals beyond their own useful range.

Some method of conducting waves from generator to antenna, and from antenna to receiver, is obviously necessary. While ordinary insulated wires can be used through the broadcast range and beyond, in the short-wave range special attention must be given to losses in the insulation, to radiation into space and into nearby conductors, and to the effects on 
tuning produced by stray capacitance and inductance. The coaxial line, in which one conductor is formed into a tube and the other is enclosed in it, is an excellent expedient. If the central conductor is completely removed, it is still possible to transmit energy down the tube, which then becomes a wave guide. If the tube is filled with insulating material, even the outer conductor can be removed. The coaxial and the conducting tube or wave guide are the most promising of these arrangements. Compared from the point of view of attenuation losses, the coaxial line is better at the lower frequencies; but in the micro-wave region, which is of most importance at the moment, the wave guide has decided advantages. However, below a certain frequency-about $3 \times 10^{\circ}$ for the wave guide-the wave guide 'cuts off' abruptly.

Wave guides are decidedly useful for conveying micro-waves from their generator to the place where they will be used. They contain no insulating material and so are entirely immune to moisture, while their waves can be radiated by simply flaring out the tube into a horn. A wave guide may also be made into a resonant chamber by blocking one end with a metal plate and closing the other partially by a plate with a hole in it. By varying the length of the chamber, it can be tuned to the precise frequency desired; with a small hole, if the chamber is $\frac{1}{2}, 1$ or $1 \frac{1}{2}$ of a wave-length, it will admit energy readily ; if $\frac{3}{4}$ or $1 \frac{1}{4}$ wave-lengths, it will repel energy, that is, be anti-resonant. Since the wave pattern in a resonator is fixed, it is possible to locate a detector at precisely the right spot in the pattern in order to obtain maximum response.

Somewhere along the frequency scale in the neighbourhood of a billion cycles per second-wave-length about one foot-micrc-wave technique undergoes a marked change. Methods using the conventional go-and-return-conductor type of circuit give way to the somewhat simpler hollow pipe, or wave guide, circuit. These newer methods seem to be at their best in the centimetre wave-length range. At the longer wave-lengths, the component parts become inconveniently large. For shorter waves, it would appear that ability to manufacture small parts would become an important limitation. What the technique will be beyond this point is a matter for the future.

\section{THE INSECTS OF GUAM}

\section{By DR. A. D. IMMS, F.R.S.}

A KNOWLEDGE of the insect fauna of small but important islands is very desirable before such fauna is inevitably changed by the operations of man and species have become extinct. In certain cases this must have happened even before some animals were discovered, as in Hawaii, for example.

The island of Guam is very isolated in the waters of the Pacific Ocean and measures nearly 30 miles long and 4-8 miles wide. A rainfall of about 90 inches per annum is usual and mostly during July-November. The northern half of the island is an elevated limestone plateau originally covered with tropical jungle, of which much still remains. Areas with sufficient soil are occupied by gardens and small farms, and there are a few small settlements. The southern half of the island includes a low volcanic range of mountains near the western shore, the highest peak being $1,334 \mathrm{ft}$. Streams on the eastern slope are the larger, and at the mouths of the valleys are located coastal villages. Much of the farming is carried on in the valleys, especially rice culture. On the plateau region are some cattle ranches. Rice is the only irrigated crop : not enough is grown to supply all needs and in 1936 importations were made from Japan. Other crops are corn, copra and many kinds of fruits and vegetables.

The foregoing remarks are mainly taken from an account entitled "Insects of Guam I.", which forms Bulletin 172 of the Bernice P. Bishop Museum, Honolulu (1942). This account is made up of some twenty-seven articles by specialists on different groups of insects, and presents the results of studies made on material collected during an entomological survey of the island in 1936. The survey was conducted under the auspices of the Hawaiian Sugar Planters' Associa. tion for the purpose of studying insects of economic importance in Guam. This island is the most important station between the Philippines and Honolulu on the route of Pan-Pacific Airways. Unknown insects were already being found in planes arriving in the Hawaiian Islands, and notwithstanding precautions by fumigation of aircraft, an occasional insect was found which had not fully succumbed. There is concern lest unknown pests, injurious to sugar cane or other Hawaiian crops, might gain an entry and become established in the archipelago. It is noteworthy in this connexion that about fifty species of pests of cultivated plants are known in Guam which are not known in Hawaii. The Sugar Planters' Association has always adopted a broadminded and scientific policy, and it recognizes that among these insects of Guam are no doubt many that would become pests should they reach the Hawaiian Islands and become established therein. Furthermore, the insect fauna of the island is very inadequately known.

Among the various groups of insects dealt with in this bulletin no discrimination is made of those of economic importance-all come in for discussion and description of their species where necessary. It is noted that eleven species of dragonflies and twentytwo species of Thysanoptera but only three species of Aphididæ and a single species of Aleurodidæ are recorded. Butterflies number fourteen species, which is in contrast to the whole Hawaiian Archipelago, which only supports ten species. The Guam butterflies are mostly immigrants, possibly some of recent arrival, as only three or four species had been previously recorded. The most notable are the 'Monarch' Danaida plexippus and Hypolimnas bolina, the latter being widely distributed in countries and islands in and bordering the Pacific Ocean. Moths are not included in this volume except the Sphingidæ, which number five species, including the cosmopolitan Herse convolvuli. Of the Coleoptera the Curculionidæ, with forty-nine species, head the list; among them no fewer than thirty-three species and eight genera are described as being new. Among Hymenoptera twenty-nine species of ants and ten species of wasps are enumerated. Of the ants nine of the species have been already recorded from the Hawaiian Islands. Only a few Diptera are included in this volume: they comprise, among others, five species of mos. quitoes, including the notorious Aedes cegypti. A second volume of the survey, dealing with other groups of insects, is promised at a later date when these studies have been completed. 